\title{
STUDIES ON DIGITALIS. II. EXTRACARDIAC EFFECTS ON VENOUS RETURN AND ON THE CAPACITY OF THE PERIPHERAL VASCULAR BED
}

\author{
By JOHN ROSS, JR., EUGENE BRAUNWALD AND JOHN A. WALDHAUSEN \\ WITH THE TECHNICAL ASSISTANCE OF ROBERT LEWIS
}

(From the Clinic of Surgery, National Heart Institute, Bethesda, Md.)

(Submitted for publication January 15, 1960; accepted February 5, 1960)

The decline in cardiac output following the administration of digitalis to experimental animals (1-5) and to normal human subjects (6-10) would appear to be inconsistent with the well known positive inotropic action of this drug. The latter has been further confirmed by direct measurement of myocardial contractile force in both man and $d o g$ in the absence of heart failure $(5,11$, 12). Peripheral pooling of blood leading to a decreased return of venous blood to the heart has been suggested by several investigators as a possible explanation for this phenomenon (13-15). Tainter and Dock (16) observed an increase in portal venous pressure following digitalis administration in the dog and postulated that hepatic vein constriction resulted in pooling of blood in the splanchnic bed. It is now clear that digitalis glycosides act directly on the peripheral circulation of both dog and man $(12,17)$. To define further the peripheral actions of these drugs, a preparation was developed which permitted characterization of the effects of digitalis on the capacity of the peripheral vascular bed and on venous return.

\section{METHODS}

Twenty-four dogs, averaging $15.0 \mathrm{~kg}$ in weight, were studied. Anesthesia was administered with morphine, chloralose and urethan; complete bypass of the heart and lungs was established, and pressure and flow measurements carried out as previously described (17). Perfusion rates were kept constant throughout each experiment and varied from 83 to 108 , averaging $97 \mathrm{ml}$

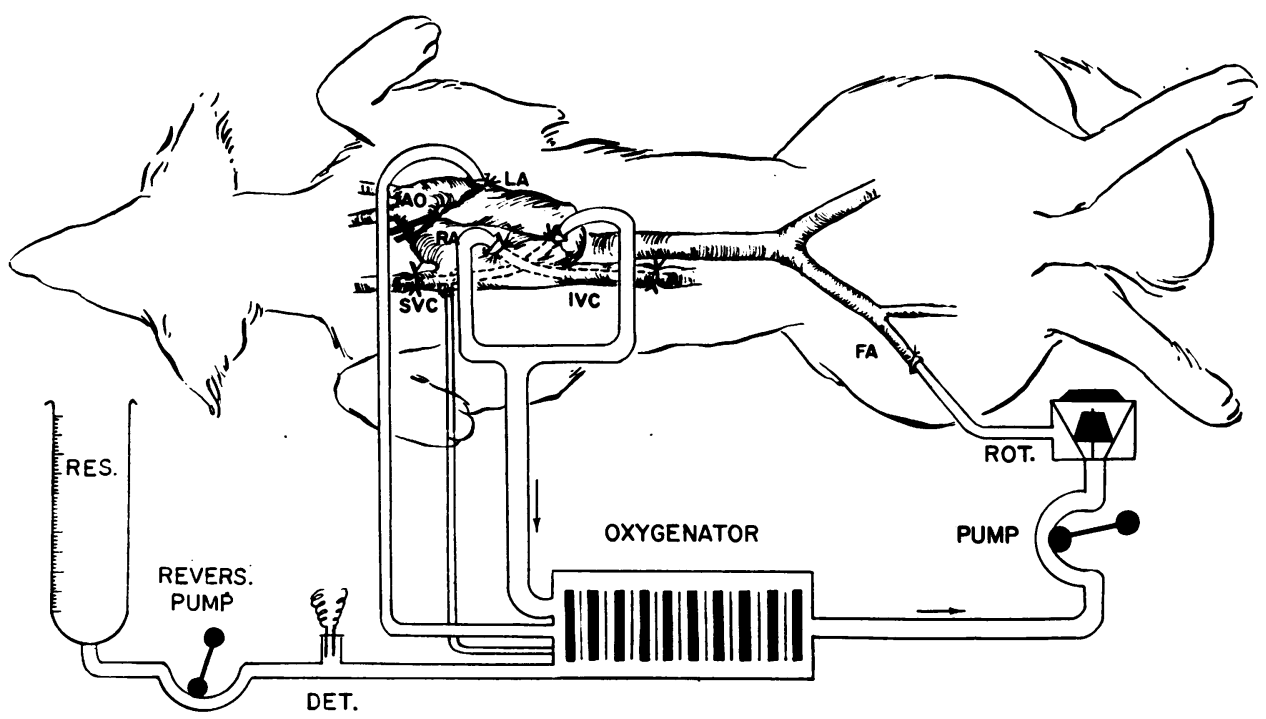

Fig. 1. Diagrammatic Representation of the extracorporeal circuit employed. Blood drains by gravity from the superior vena cava (SVC) and inferior vena cava (IVC) to the oxygenator. The aorta (AO) is cross-clamped above the coronary arteries and blood accumulation in the right atrium (RA) and left atrium (LA) is prevented by means of two drains. Oxygenated blood is pumped through a rotameter (ROT.) into the femoral artery (FA). The level of blood in the oxygenator is sensed by the detecting electrodes (DET.) which activate a reversible pump connected with the calibrated reservoir (RES.). 
per $\mathrm{kg}$ body weight per minute. In the present experiments accumulation of blood in the heart and lungs, resulting from bronchial arterial flow, was prevented by means of two cannulae which drained blood from the right and left atria to the venous side of the oxygenator. In addition, a device for the measurement of alterations in the volume of blood in the extracorporeal circuit (18) was incorporated in 18 of the 24 experiments (Figure 1). Changes in the level of blood in the oxygenator were detected by electrodes. Blood was then automatically added to or removed from a calibrated reservoir by a reversible pump which maintained a constant volume of

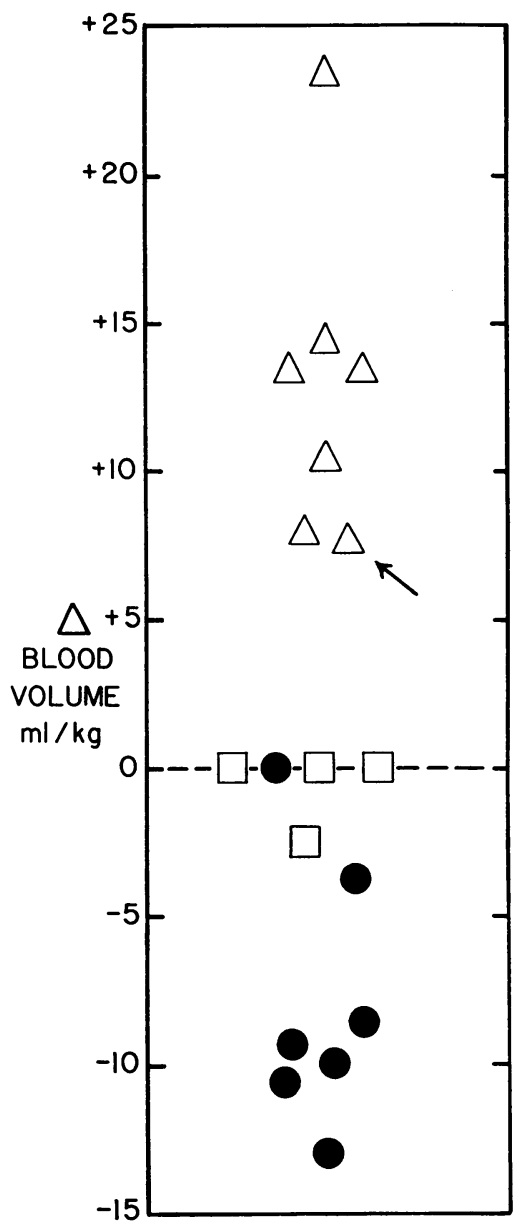

Fig. 2. Alterations in intravascular BLood volUME, IN MILLILITERS PER KILOGRAM OF DOG TOTAL BODY WEIGHT, RESUlting From aCUTE digitalization. The arrow indicates the single experiment in which lanatoside $\mathrm{C}$ was administered. Open triangles: dogs in which the portal vein was not vented. Open squares: dogs in which the portal vein was vented but in which a small elevation of portal venous pressure occurred after digitalization. Closed circles: dogs in which the portal vein was vented and in which portal venous pressure remained unchanged after digitalization. blood in the oxygenator. Thus, alterations in extracorporeal blood volume, which reflected reciprocal changes in the intravascular blood volume, were measured at 1 minute intervals.

In 11 of the $18 \mathrm{dogs}$ in which volume alterations were measured, an additional abdominal incision was made, and a T-tube was inserted into the portal vein. One limb of this provided a low resistance pathway to the venous side of the oxygenator, thereby decompressing and preventing blood accumulation in the splanchnic bed. In 5 of these dogs, more effectively to prevent pooling, the splanchnic arteries were also ligated. In addition to the arterial pressure, venous pressure was measured by means of a catheter, the tip of which was placed in the lower inferior vena cava. In 6 additional experiments, in which volume alterations were not measured, a catheter was inserted via the external jugular vein into the superior vena cava just within the thorax, and both superior and inferior vena caval pressures were measured. In the 11 dogs in which a laparotomy was performed, pressure was measured in the portal vein by means of a catheter inserted into a small mesenteric vein. All pressures were measured with Statham pressure transducers and recorded continuously. Following a control period of at least 20 minutes, 0.60 to 0.75 cat unit per $\mathrm{kg}$ of acetylstrophanthidin was injected into the oxygenator. In one experiment, 0.5 cat unit per $\mathrm{kg}$ lanatoside $\mathrm{C}$ was administered. In the dogs receiving acetylstrophanthidin, the alterations in blood volume presented are those existing at the time the blood pressure elevation resulting from digitalization had returned to the control level (17). In the dog receiving lanatoside $\mathrm{C}$ the pressor response persisted and the volume change presented is that which existed at the time when both arterial pressure and blood volume had stabilized.

\section{RESULTS}

Portal circulation intact. In all seven dogs subjected to cardiopulmonary bypass without portal decompression, a marked decrease in venous return to the oxygenator was observed following acetylstrophanthidin or lanatoside $\mathrm{C}$ injection. In order to maintain oxygenator volume and perfusion rate constant, it was necessary to transfuse the dog-oxygenator circuit from the calibrated reservoir. This augmentation of intravascular blood volume ranged from 120 to $300 \mathrm{ml}$ and averaged $190 \mathrm{ml}$, representing $12.7 \mathrm{ml}$ per $\mathrm{kg}$. (Figure 2). In the six dogs of this group in which acetylstrophanthidin was administered, the arterial pressor response began within one minute following injection. The shift of blood from the reservoir to the dog began later (from three to six minutes after injection reached a maximum level after the peak of the pressor response had passed) and 


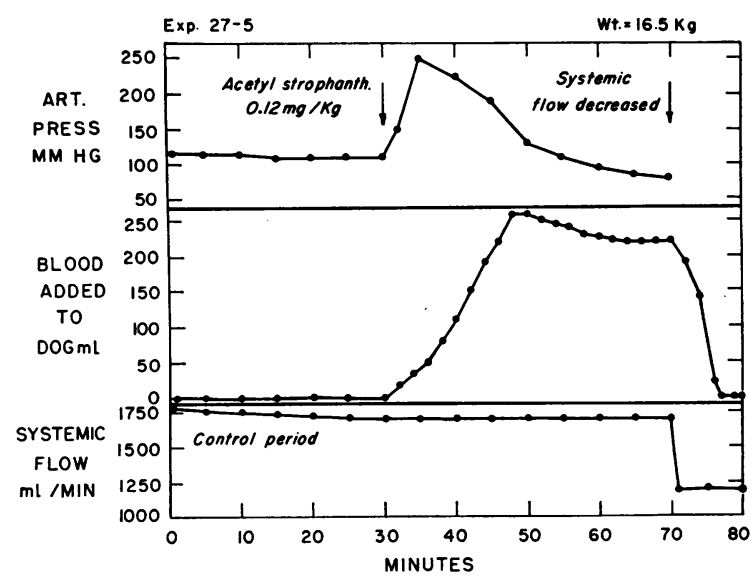

Fig. 3. Observations during a 30 minute control PERIOD AND A 50 MINUTE PERIOD FOLLOWING THE INJECTION OF ACETYLSTROPHANTHIDIN AT THE FIRST VERTICAL ARROw. At the second vertical arrow, after the pressor response had been dissipated, the pump output was decreased until the control blood volume was restored.

then persisted. In three of these six dogs, after the maximum shift of blood had occurred, systemic flow was progressively decreased until the intravascular blood volume that existed during the control period was restored (Figure 3 ). These reductions in perfusion rate were 16,17 and 30 per cent, respectively, of the systemic flow during the control period and indicate the magnitude of

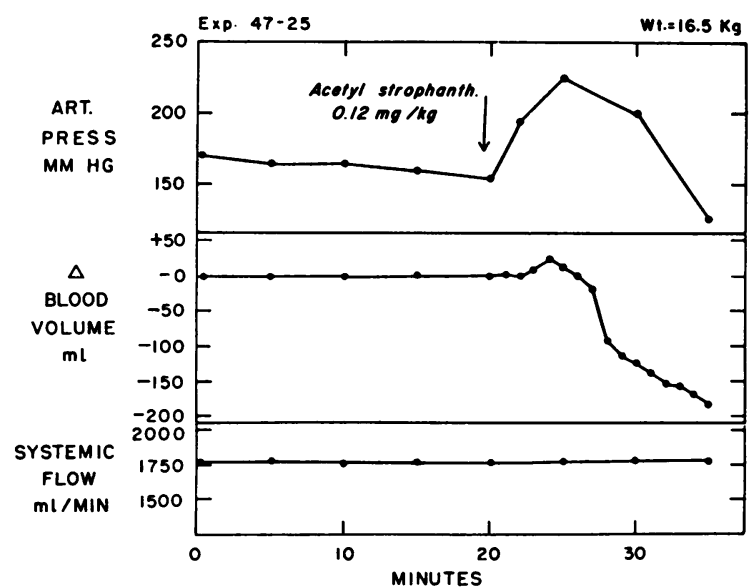

Fig. 4. Observations during a 20 minute control PERIOD, AFTER WHICH, AT THE VERTICAL ARROW, ACETYLSTROPHANTHIDIN WAS INJECTED INTO A DOG IN WHICH THE PORTAL VEIN WAS VENTED AND IN WHICH PORTAL VENOUS PRESSURE REMAINED CONSTANT. The decline in intravascular volume is indicated in the middle frame. the decline in venous return following acetylstrophanthidin administration.

Portal vein decompressed. In 4 of the 11 dogs in which portal vein decompression was attempted, venting was apparently incomplete and a small, sustained increase in portal pressure $(1$ to $6 \mathrm{~cm}$ $\mathrm{H}_{2} \mathrm{O}$ ) was observed following acetylstrophanthidin administration. In these four dogs, as shown in Figure 2, no significant alterations in extracorporeal blood volume following digitalization were observed. In the remaining seven dogs, including all five with splanchnic artery ligation, portal venous pressure did not increase following

$\operatorname{Dog} \# 31-9$
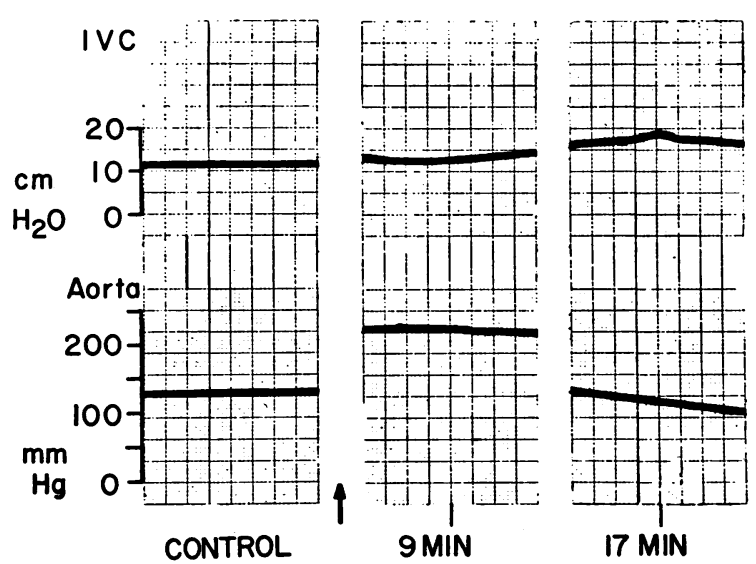

FIG. 5. MEAN PRESSURES RECORDED IN THE INFERIOR VENA CAVA (IVC) AND AORTA DURING A CONTROL PERIOD AND 9 AND 17 MINUTES FOLLOWING DigitAlizATION. Acetylstrophanthidin, 0.75 cat $U$ per $\mathrm{kg}$, was administered at the arrow. Each large vertical division represents 20 seconds. At 17 minutes arterial pressure is declining and inferior vena caval pressure is above the control level.

acetylstrophanthidin administration. In six of these seven dogs venous return to the oxygenator increased, resulting in a diminution of intravascular blood volume ranging from 50 to $190 \mathrm{ml}$ and averaging $150 \mathrm{ml}$ or $7.6 \mathrm{ml}$ per $\mathrm{kg}$ (Figure 2). A representative experiment of this type is illustrated in Figure 4.

$V$ enous pressure alterations. Inferior vena caval pressure was measured in 22 of the 24 dogs. In 12 dogs without portal decompression, a rise in inferior vena caval pressure ranging from 0.2 to 5.0 , averaging $2.4 \mathrm{~cm} \mathrm{H}_{2} \mathrm{O}$, had occurred at the time the arterial pressure had returned to con- 
trol levels (Figure 5). In six of these dogs, superior vena caval pressure was also measured, and elevations ranging from 0.5 to 5.0, averaging $2.7 \mathrm{~cm} \mathrm{H}_{2} \mathrm{O}$, were noted. In 8 of $10 \mathrm{dogs}$ with portal decompression, increases in inferior vena caval pressure occurred which ranged from 1 to 5 $\mathrm{cm} \mathrm{H}_{2} \mathrm{O}$ and averaged $1.6 \mathrm{~cm} \mathrm{H}_{2} \mathrm{O}$. In one of the remaining two dogs, a $2 \mathrm{~cm}$ decline in inferior vena caval pressure was observed, while in the other dog no change was noted.

\section{DISCUSSION}

The present experiments in the dogs with intact portal circulations demonstrate pooling of blood in the portal venous system of sufficient magnitude to effect a substantial decrease in venous return. These observations offer a possible explanation for the decline in cardiac output that occurs following digitalization in the presence of a normal heart and complete circulation. The present study is consonant with the observations of Cotten and Stopp (5) who observed that cardiac output increased following digitalization only when left atrial pressure was maintained by means of blood infusions. The actual quantities of blood trapped in the splanchnic bed were probably larger than the augmentation of the total intracorporeal blood volume indicated, since a reduction in intravascular blood volume was observed when portal pooling was completely prevented. In the experiments in which the portal circulation was intact, the decrease in the extrasplanchnic blood volume was presumably not apparent because of the greater increase of blood volume in the splanchnic system. It is suggested that this decline of intravascular volume, which occurred at a constant perfusion rate and at a time when the arterial pressure had returned to the predigitalization level, was due to a contraction of that portion of the peripheral circulatory bed containing the major portion of the blood volume, the systemic venous system (19). Such a contraction of blood volume is similar to that which we and others (20-22) have observed following the administration of pressor amines, the venoconstrictor action of which is well known $(23,24)$.

The consistent elevation of both vena caval pressures following digitalization represents an increase in the pressure gradient between the site of pressure measurement in the venae cavae and the constant level of the blood in the oxygenator. Since the total perfusion rate and the size and position of the extracorporeal conduits were also unchanged, this increased pressure gradient presumably reflected a diminished cross-sectional area of the venae cavae, and further supports the hypothesis that generalized venoconstriction occurred. Somewhat similar observations on inferior caval pressure, following the administration of digitalis to sheep, were made by Tyrer (25).

The use of a short-acting digitalis preparation, acetylstrophanthidin, facilitated the demonstration of these hemodynamic changes. The rapidity with which displacement of blood occurred, both into and out of the dogs, suggests that actual alterations in intravascular capacity took place rather than shifts of fluid between the intravascular and extravascular compartments. With digitalis preparations having a more delayed onset of action, fluid shifts resulting from persistent alterations in hemodynamics might occur and mask the changes in blood volume observed in this preparation.

In other reports, a strong pressor effect of digitalis both in the $\operatorname{dog}(17)$, and in patients (12) undergoing cardiopulmonary bypass was reported. The present experiments indicate that digitalis glycosides also have a venoconstrictor action in the dog. Further support for this hypothesis is provided by the observations of a constrictor action of digitalis on isolated vein segments $(24,26)$. Similarly, an increase in the venous tone in the forearm of human subjects following digitalization has recently been demonstrated by Horsely and Eckstein (27). Although the differences in the smooth muscle content of the hepatic veins in $\operatorname{dog}$ and man are well recognized (28), it has also recently been suggested that hepatic venoconstriction and splanchnic pooling of blood may occur in man. Baschieri, Ricci, Mazzuoli and Vassalle (29) have observed an elevation of hepatic venous wedge pressure, an increase in the gradient between the hepatic venous wedge and inferior vena caval pressures, and a decline in hepatic blood flow following digitalization of normal human subjects. Thus, both experimental and clinical observations of extracardiac vascular effects of digitalis indicate that peripheral as well as inotropic actions play a role in the hemody- 
namic alterations following digitalis administration.

\section{SUM MARY}

The effects of the administration of acetylstrophanthidin on venous return and on the capacity of the peripheral vascular bed were studied in dogs, utilizing a preparation in which the cardiac effects of the drug were excluded. In the seven dogs in which the portal circulation was intact, a decline in venous return, and a consequent intravascular pooling of blood, averaging $12.7 \mathrm{ml}$ per $\mathrm{kg}$ body weight, occurred. In the six dogs in which pooling in the splanchnic bed was prevented, an increase in venous return and a decline in intravascular volume, averaging 7.6 $\mathrm{ml}$ blood per $\mathrm{kg}$ body weight, was noted. In 22 of 24 dogs small elevations of inferior vena caval pressure were observed. In the six dogs in which superior vena caval pressure was also measured, a similar increase occurred. The data presented are consistent with the hypothesis that in the dog, digitalis induces a generalized venoconstriction, most striking in the hepatic veins.

\section{REFERENCES}

1. Harrison, T. R., and Leonard, B. W. The effect of digitalis on the cardiac output of dogs and its bearing on the action of the drug in heart disease. J. clin. Invest. 1926, 3, 1.

2. Cohn, A. E., and Stewart, H. J. The relation between cardiac size and output per minute following the administration of digitalis in normal dogs. J. clin. Invest. 1928, 6, 53.

3. Cohn, A. E., and Stewart, H. J. The relation between cardiac size and cardiac output per minute following the administration of digitalis in dogs in which the heart is enlarged. J. clin. Invest. 1928, $6,79$.

4. Regan, T. J., Talmers, F. N., and Hellems, H. K. Myocardial transfer of sodium and potassium: Effect of acetyl strophanthidin in normal dogs. J. clin. Invest. 1956, 35, 1220.

5. Cotten, M. D., and Stopp, P. E. The action of digitalis on the nonfailing heart of the dog. Amer. J. Physiol. 1958, 192, 114.

6. Stewart, H. J., and Cohn, A. E. Studies on the effect of the action of digitalis on the output of blood from the heart. III. The effect on the output in normal human hearts. J. clin. Invest. 1932, 11, 917.

7. McMichael, J., and Sharpey-Schafer, E. P. Action of intravenous digoxin in man. Quart. J. Med. 1944, 13, 123.
8. Bing, R. J., Maraist, F. M., Dammann, J. F., Jr., Draper, A., Jr., Heimbecker, R., Daley, R., Gerard, R., and Calazel, P. Effect of strophanthus on coronary blood flow and cardiac oxygen consumption of normal and failing human hearts. Circulation 1950, 2, 513.

9. Harvey, R. M., Ferrer, M. I., Cathcart, R. T., and Alexander, J. K. Some effects of digoxin on the heart and circulation in man. Digoxin in enlarged hearts not in clinical congestive failure. Circulation 1951, 4, 366.

10. Williams, M. H., Jr., Zohman, L. R., and Ratner, A. C. Hemodynamic effects of cardiac glycosides on normal human subjects during rest and exercise. J. appl. Physiol. 1958, 13, 417.

11. Walton, R. P., Leary, J. S., and Jones, H. P. Comparative increase in ventricular contractile force produced by several cardiac glycosides. J. Pharmacol. exp. Ther. 1950, 98, 346.

12. Bloodwell, R. D., Goldberg, L. I., Braunwald, E., Gilbert, J. W., Ross, J., Jr., and Morrow, A. G. Myocardial contractility in man: The acute effects of digitalis, sympathomimetic amines and anoxic cardiac arrest. Surg. Forum 1959, 10, 532.

13. Katz, L. N., Rodbard, S., Friend, M., and Rottersman, W. The effect of digitalis on the anesthetized dog. I. Action on the splanchnic bed. J. Pharmacol. exp. Ther. 1938, 62, 1.

14. Dock, W., and Tainter, M. L. The circulatory changes after full therapeutic doses of digitalis, with a critical discussion of views on cardiac output. J. clin. Invest. 1930, 8, 467.

15. McMichael, J. Pharmacology of the failing human heart. Brit. med. J. 1948, 2, 927.

16. Tainter, M. L., and Dock, W. Further observations on the circulatory actions of digitalis and strophanthus with special reference to the liver, and comparisons with histamine and epinephrine. J. clin. Invest. 1930, 8, 485.

17. Ross, J., Jr., Waldhausen, J. A., and Braunwald, E. Studies on digitalis. I: Direct effects on peripheral vascular resistance. J. clin. Invest. 1960, 39, 930.

18. Waldhausen, J. A., Ross, J., Jr., Lombardo, C. R., Cooper, T., Gilbert, J. W., and Morrow, A. G. Flow and volume regulation during cardiopulmonary bypass: The use of an electromagnetic flowmeter and a device for the automatic control of oxygenator volume. Trans. Amer. Soc. Artif. intern. Organs 1959, 5, 172.

19. Green, H. D. Circulation: Physical principles in Medical Physics, O. Glasser, Ed. Chicago, Year Book Publ., 1944, vol. 1, p. 208.

20. Rose, J. C., and Freis, E. D. Alterations in systemic vascular volume of the dog in response to hexamethonium and norepinephrine. Amer. J. Physiol. 1957, 191, 283. 
21. Rashkind, W. J., Lewis, D. H., Henderson, J. B., Heiman, D. F., and Dietrick, R. B. Venous return as affected by cardiac output and total peripheral resistance. Amer. J. Physiol. 1953, 175, 415.

22. Crawford, A. C., and Twombly, M. M. Notes on the response of veins to epinephrin. N. Y. med. J. 1913, 98, 327 .

23. Franklin, K. J. The pharmacology of the isolated vein ring. J. Pharmacol. exp. Ther. 1925, 26, 215.

24. Leonard, E., and Sarnoff, S. J. Effect of aramineinduced smooth muscle contraction on lengthtension diagrams of venous strips. Circulat. Res. 1957, 5, 169.
25. Tyrer, J. H. The peripheral action of digoxin on venous pressure: A study using sheep with an "artificial heart." Med. J. Aust. 1952, 1, 497.

26. Leonard, E. Personal communication.

27. Horsely, A. W., and Eckstein, J. W. The effect of acetyl strophanthidin on peripheral venous tone in man (abstract). J. Lab. clin. Med. 1959, 54, 827.

28. Bauer, W., Dale, H. H., Poulsson, L. T., and Richards, D. W. The control of circulation through the liver. J. Physiol. 1932, 74, 343.

29. Baschieri, L., Ricci, P. D., Mazzuoli, G. F., and Vassalle, M. Studi su la portata epatica nell'uomo: Modificazioni del flusso epatico da digitale. Cuore e Circol. 1957, 41, 103. 